\title{
BJSM
}

\section{A 12-month prospective cohort study of injury in international rowers}

F Wilson, C Gissane, J Gormley, et al.

Br J Sports Med 2010 44: 207-214 originally published online August 21, 2008

doi: $10.1136 / \mathrm{bjsm} .2008 .048561$

Updated information and services can be found at:

http://bjsm.bmj.com/content/44/3/207.full.html

These include:

References This article cites 25 articles, 15 of which can be accessed free at: http://bjsm.bmj.com/content/44/3/207.full.html\#ref-list-1

Email alerting Receive free email alerts when new articles cite this article. Sign up in the service box at the top right corner of the online article.

Notes

To request permissions go to:

http://group.bmj.com/group/rights-licensing/permissions

To order reprints go to:

http://journals.bmj.com/cgi/reprintform

To subscribe to BMJ go to:

http://journals.bmj.com/cgi/ep 


\title{
A 12-month prospective cohort study of injury in international rowers
}

\author{
F Wilson, ${ }^{1}$ C Gissane, ${ }^{2}$ J Gormley, ${ }^{1}$ C Simms ${ }^{3}$
}

\begin{abstract}
${ }^{1}$ School of Physiotherapy, Trinity College, Dublin, Ireland; ${ }^{2} \mathrm{St}$ Mary's University College, Twickenham, Middlesex, UK ${ }^{3}$ Department of Mechanical Engineering., Trinity College, Dublin, Ireland
\end{abstract}

Correspondence to: Fiona Wilson, School of Physiotherapy, Trinity Centre for Health Sciences, St James's Hospital, Dublin 8, Ireland; wilsonf@tcd.ie

Accepted 15 July 2008 Published Online First 21 August 2008

\author{
ABSTRACT \\ Objective: In this study, the injury incidence and \\ association with type and volume of training in \\ international rowers were described.
}

Design: A prospective cohort design was used over a 12month period.

Patients: 20 international rowers who were competing as part of the Irish Amateur Rowing Union squad system. Methods: The rowers were interviewed monthly, and data were collected regarding their training and competition exposure as well as their injury experience. Results: A mean injury rate of 3.67 per 1000 exposure hours was reported with a total of 44 injuries reported in a 12-month period. The mean number of injuries sustained per athlete was 2.2 (1.24) over the 12-month period. The area where the greatest number of injuries were reported was the lumbar spine $(31.82 \%$ of total injuries, 95\% Cl 20 to 50 ) (fig 2) followed by the knee (15.91\% of total injuries, $95 \% \mathrm{Cl} 10$ to 30$)$ and the cervical spine $(11.36 \%$ of total injuries, $95 \% \mathrm{Cl} 5$ to 24). Half of the injuries (22 injuries, $50 \%$ of total reported injuries) were to the spine $\left(\chi^{2}=30.8, d f=9, p=0.0003\right)$. Ergometer training load was the most significantly associated with injury risk $(r=0.68, p=0.01)$.

Conclusion: International rowers are at higher risk of injury than most non-contact sports and some contact sports. The high risk of lumbar spine injury and the significant association of high volume of ergometer training merit further research to reduce time and competition lost to injury.

Rowing is a sport that demands high levels of training and commitment. In recent years, this has seen most international athletes train full time at least twice and up to four times a day. Despite these high training volumes, there has been limited attention paid to the study of rowing injury patterns and risk factors. A search of PubMed, Embase, Science Direct, Cinahl and Amed did not reveal any prospective cohort studies of rowing injury. Published studies either comprise a retrospective review of medical notes ${ }^{1}$ or retrospective questionnaires, ${ }^{2}$ which are unable to provide standardised injury rates per $1000 \mathrm{~h}$, or fully describe risk factors. Other published studies are focused on more specific examination of specific injuries, ${ }^{3-11}$ such as back pain or chest wall injuries. Despite this, there is still some clinical evidence that rowers experience injuries that both compromise effective training and competition and result in careers being ended prematurely. Thus, there is a need for a prospective cohort study to establish an injury profile and to identify risk factors for injury in rowers.

The aim of this study was to carry out a 12month prospective study of injury in international rowers to establish an injury profile for the sport and to identify training and competition patterns to establish common risk factors. A further objective of the study was to pilot a research tool that could be used on a large cohort in the future.

\section{METHODS \\ Study design}

The study design was a prospective cohort study carried out over a 12-month period on international rowers competing as part of the Irish Amateur Rowing Union squad system. Data were recorded monthly by telephone interview. Ethics were passed internally by the Trinity College School of Physiotherapy, written informed consent was obtained from the Irish Amateur Rowing Union and the athletes involved.

\section{Participants}

The subject group examined in this study were senior male and female international rowers. All were training and competing as part of the Irish Team and were confirmed by the head coach to be potential athletes to compete at the 2004 Olympic Games, World Senior or under-23 World Championships. The head coach provided a list and contact details of all athletes with such potential for the 2003/2004 season. To be eligible for the study, all athletes had to be over 18 years of age and had to have gained national colours in the previous 2 years. Participants in the study were provided with full details of the study and signed a consent form confirming enrolment in the study and acknowledged the confidentiality of their personal details.

\section{Measurement questionnaire and procedure}

The chief investigator called each athlete once a month for 12 months. The telephone interview was structured and consisted of mostly close-ended questions that gathered details regarding hours, type of training and racing, and injury experience. The chief investigator was a chartered physiotherapist who interpreted injury reports to give a diagnosis in cases where the athlete had not been seen by a physiotherapist or medical professional.

The monthly questionnaire was adapted from the Rugby Injury and Performance Project. ${ }^{12}$ All athletes completed a baseline questionnaire to establish details such as date of birth, occupation and international rowing experience as well as injury details for the previous 12 months. The monthly questionnaire comprised three sections, the first of which examined details of the volume and type of training that the athlete took part in the previous month. Details were also collected 
regarding warm up and warm down procedures and also any training or racing that was missed because of injury or illness. The second section noted if the athlete had experienced injuries over the previous month. If an injury was sustained, it was established if it was a result of rowing or rowing training. If it was as a result of rowing or rowing training, details were documented in section 3. Section 3 examined detailed aspects of the injury including site, mode of onset and treatment received. It was also established if the athlete has previously injured this area.

\section{Injury definition}

For the purposes of this project, an injury was defined as a problem that caused the athlete to miss:

- At least one competition (regatta, head race or trial) OR

- At least two training sessions OR

- Required at least one visit to a health professional for treatment.

This definition was adapted from the Rugby Injury and Performance Project ${ }^{12}$ (RIPP).

\section{Statistical analysis}

Results were entered into an excel spreadsheet and analysed by calculating percentages and injury rates per $1000 \mathrm{~h}$. All computations involving a 95\% CI were calculated using the Confidence Interval Analysis Package. ${ }^{13}$ Further analysis involved the use of $\chi^{2}$, Pearson's correlation and regression analysis, which were computed using SPSS V.15.

\section{RESULTS}

Of the 26 athletes who were contacted, 20 agreed to take part. All 20 were contacted and supplied training and injury details throughout the study, although one athlete was unable to return to full training and racing following illness. Of the cohort, 12 were men and 8 were women with a mean age of 26.25 (4.18 years) and a mean number of years of rowing experience of 10.9 (3.84 years). Fifteen of the team described themselves as lightweight rowers and five as heavyweight rowers, although the lightweights would generally only be "on weight" at specific times of the season. All rowers were training full time as the data were collected during the year of the Olympic Games.
A mean injury rate of 3.67 per $1000 \mathrm{~h}$ (training and competing) was reported with a total of 44 injuries reported in a 12-month period. A total of 12905.3 (mean 645.27 $(167.05 \mathrm{~h})$ ) was spent training and a total of 61.49 (mean 3.07(1.1 h)) was spent competing. The total time spent training and racing was $12956.79 \mathrm{~h}$ for the 12-month period, and the mean time was $647.84 \mathrm{~h}(167.54 \mathrm{~h})$. The mean number of injuries sustained per athlete was 2.2 (1.24) over the 12-month period. The month when the greatest number of injuries were sustained was November (14 injuries reported), and the lowest number of injuries were in July and August when no injuries were reported (see fig 1 and table 2).

\section{Subcategories of injury}

Only one athlete missed any racing as a result of injury (lumbar disc injury). All but one athlete (Achilles tendonitis) visited a health professional, and this athlete's injury fell under the subcategory of "missed at least two training sessions". Thus, 42 injuries were defined under the subcategory of requiring a visit to a health professional.

\section{Injury reporting}

Two athletes did not see either a chartered physiotherapist who was part of the IARU system, or a medical doctor. One athlete attended a chiropractor and was diagnosed with sacro-iliac joint (SIJ) dysfunction, and one did not seek treatment but reported Achilles tendonitis, a condition for which he had been previously treated by a chartered physiotherapist. In these two instances, the chief investigator confirmed the diagnosis. All other injuries (42) were diagnosed by chartered physiotherapists or medical doctors.

\section{Individual injury rates}

The individual injury rates including the representation of acute versus chronic or recurring injuries are reported in table 2. All injuries were newly reported so those marked as chronic or recurring had been sustained by the athlete before. No injuries carried over from 1 month to another. There were three reports of the same injury returning in the 12-month period; two cervical spine injuries and one thoracic spine injury.

Figure 1 Injury counts per month.

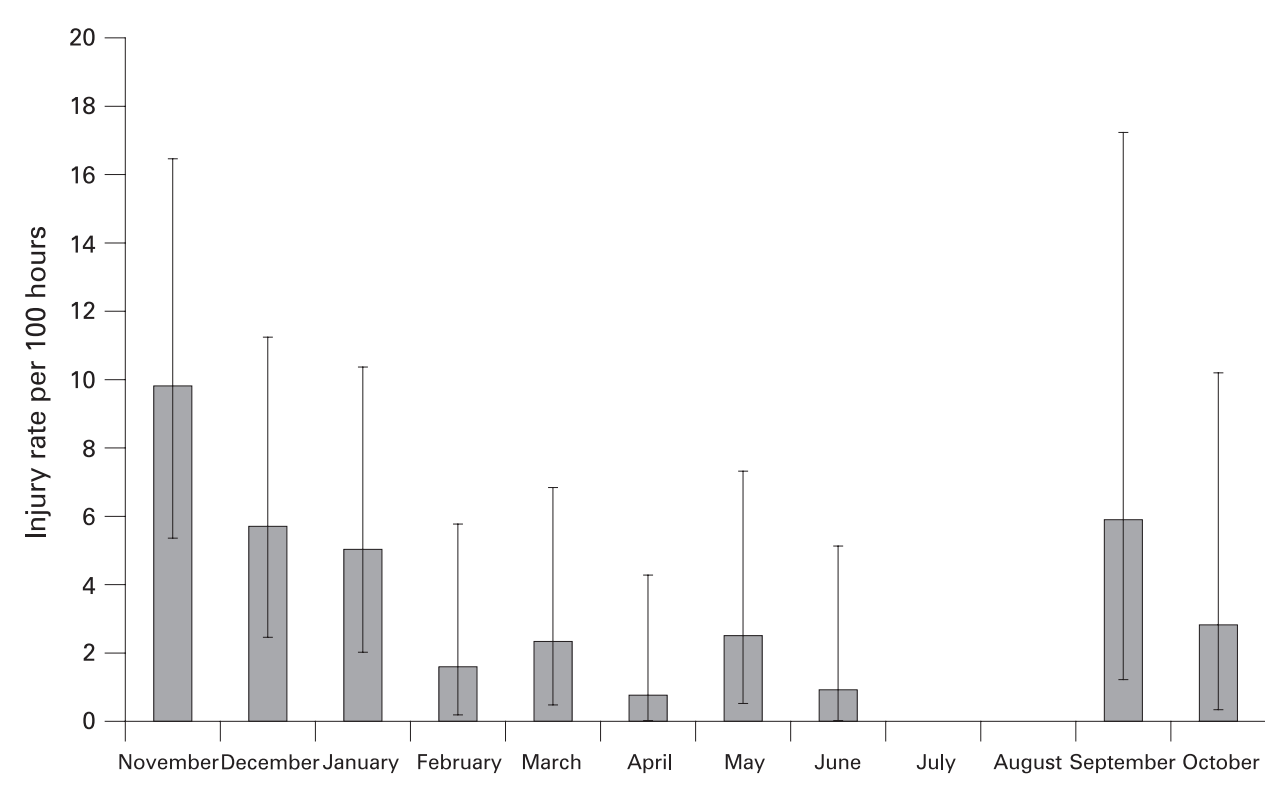


Table 1 Individual injury counts for each area

\begin{tabular}{lcl}
\hline Injury area & Injuries & $\%$ \\
\hline L spine & 14 & 31.82 \\
Knee & 7 & 15.91 \\
C spine & 5 & 11.36 \\
Wrist & 4 & 9.09 \\
SIJ & 3 & 6.82 \\
T spine & 3 & 6.82 \\
Thigh & 2 & 4.55 \\
Shoulder & 2 & 4.55 \\
Ankle & 2 & 4.55 \\
Calf & 1 & 2.27 \\
Foot & 1 & 2.27 \\
Total & 44 & \\
\hline
\end{tabular}

C, cervical; L, lumbar; SIJ, sacro-iliac joint; T, thoracic.

\section{Site of injury}

The area where the greatest number of injuries were reported was the lumbar spine (31.82\% of total injuries, 95\% CI 20 to 50) (fig 2) followed by the knee (15.91\% of total injuries, 95\% CI 10 to 30$)$ and the cervical spine $(11.36 \%$ of total injuries, $95 \%$ CI 5 to 24 ). Half of the injuries (22 injuries, $50 \%$ of total reported injuries) were to the spine $\left(\chi^{2}=30.8, d f=9, p=0.0003\right)$.

\section{Type of injury}

The types of injury experienced by the rowers are shown in table 3 . There were significant differences between the numbers in each category $\left(\chi^{2}=53, \mathrm{df}=9, \mathrm{p}<0.0001\right)$. "Spinal facet joint" injuries were the most commonly reported injury at $31.8 \%$ of the total injuries followed by tendonitis (27.27\%) and lumbar disc and muscle strain at $11.36 \%$.

"Facet joint injury" was reported of spinal joints by chartered physiotherapists on all occasions. Of the injuries that were reported as "tendonitis", three were of the wrist (not specifically reported as tenosynovitis or intersection syndrome), six were at the knee (one patella tendon, one ITB, two biceps femoris, two pes anserinus) one tibialis posterior and two Achilles tendon. Of those reported as muscle strain, two were of hamstrings, one quadriceps and two of lumbar spine musculature. Compartment syndrome of the forearm was reported as an acute injury that did not require surgery. Contusion was reported of the lower back following a boat crash, and fracture was reported at the first metatarsal. Patellofermoral joint syndrome was diagnosed by a chartered physiotherapist when an athlete presented with anterior knee pain.

\section{Relationship between number of injuries and training volume}

The monthly injury rates and training volumes are shown in table 4 . There was a non-significant correlation between monthly total training time and injury, and between mean training time and injury (both $r=0.543, p=0.068$ ). When examining the specific training type volumes, there were significant associations between monthly ergometer time and injury $(r=0.75, p=0.01)$, time spent training with heavy weights and injury $(r=0.66$, $p=0.02)$ and time spent on core stability and injury $(r=0.68$, $p=0.01)$. There were also non-significant correlations for time spent on flexibility and injury $(r=0.53, p=0.08)$, time training in a boat and injury $(r=-0.001, p=1.0)$ and time spent on lightweights and injury $(r=0.009, p=0.77)$.

Each of the significant correlations was put into a backwards multiple regression model. Each progressive model was significant, and it was determined that time on heavy weights accounted for $3.4 \%$ of the variation in the number of injuries, while core stability time accounted for $0.5 \%$ of the variation and ergometer time $51.2 \%$.

Table 5 represents the relationship between the type of training expressed as number of sessions and the injury rate for individual months.

Table 2 Training, racing and injury rate profiles for each subject including the number of acute versus chronic or recurring injuries

\begin{tabular}{|c|c|c|c|c|c|c|c|c|}
\hline Subject & $\begin{array}{l}\text { Training } \\
\text { hours }\end{array}$ & $\begin{array}{l}\text { Racing } \\
\text { hours }\end{array}$ & $\begin{array}{l}\text { Total training }+ \\
\text { racing hours }\end{array}$ & Injuries & (Acute) & $\begin{array}{l}\text { (Chronic/ } \\
\text { recurring) }\end{array}$ & $\begin{array}{l}\text { Injuries/ } \\
1000 \text { hours }\end{array}$ & $\begin{array}{l}95 \% \mathrm{CI} \text { for } \\
\text { injury rate }\end{array}$ \\
\hline 1 & 957.3 & 4.94 & 962.24 & 1 & 1 & 0 & 1.0 & 0 to 5.8 \\
\hline 2 & 509 & 2.76 & 511.76 & 4 & 4 & 0 & 7.8 & 2.1 to 20 \\
\hline 3 & 491 & 3.99 & 494.99 & 2 & 2 & 0 & 4.0 & 0.5 to 14.6 \\
\hline 4 & 704.8 & 4.44 & 709.24 & 3 & 2 & 1 & 4.2 & 0.9 to 12.4 \\
\hline 5 & 547.4 & 3.5 & 550.9 & 1 & 1 & 0 & 1.8 & 0 to 10.1 \\
\hline 6 & 726.3 & 4.88 & 731.18 & 2 & 1 & 1 & 2.7 & 0.3 to 9.9 \\
\hline 7 & 916.5 & 2.2 & 918.7 & 3 & 3 & 0 & 3.3 & 0.7 to 9.5 \\
\hline 8 & 697.7 & 3.02 & 700.72 & 3 & 2 & 1 & 4.3 & 0.9 to 12.5 \\
\hline 9 & 663.9 & 4.69 & 668.59 & 2 & 2 & 0 & 3.0 & 0.4 to 10.8 \\
\hline 10 & 616 & 2.46 & 608.46 & 2 & 0 & 2 & 3.3 & 0.4 to 11.7 \\
\hline 11 & 503.4 & 2.73 & 506.13 & 0 & 0 & 0 & 0.0 & - \\
\hline 12 & 436 & 0.93 & 436.93 & 3 & 3 & 0 & 6.9 & 1.4 to 20.1 \\
\hline 13 & 585.1 & 2.8 & 587.9 & 1 & 1 & 0 & 1.7 & 0 to 9.5 \\
\hline 14 & 1011.5 & 3.77 & 1015.27 & 2 & 2 & 0 & 2.0 & 0.2 to 9.7 \\
\hline 15 & 503.4 & 3.16 & 506.56 & 4 & 3 & 1 & 7.9 & 2.2 to 20.2 \\
\hline 16 & 597.6 & 3.08 & 600.68 & 4 & 3 & 1 & 6.7 & 1.8 to 17 \\
\hline 17 & 424.8 & 2.26 & 427.06 & 3 & 3 & 0 & 7.0 & 1.4 to 20.5 \\
\hline 18 & 583.3 & 2.52 & 585.82 & 0 & 0 & 0 & 0.0 & - \\
\hline 19 & 774.4 & 1.02 & 775.42 & 1 & 1 & 0 & 1.3 & 0 to 7.2 \\
\hline 20 & 655.9 & 2.34 & 658.24 & 3 & 1 & 2 & 4.6 & 0.9 to 13.3 \\
\hline Total & 12905.3 & 61.49 & 12956.79 & 44 & 35 & 9 & & \\
\hline Mean & 645.265 & 3.075 & 647.840 & 2.2 & & & 3.673 & \\
\hline SD & 167.055 & 1.135 & 167.537 & 1.23969 & & & 2.497 & \\
\hline
\end{tabular}


Figure 2 Types of injuries received represented as a percentage of total injuries.

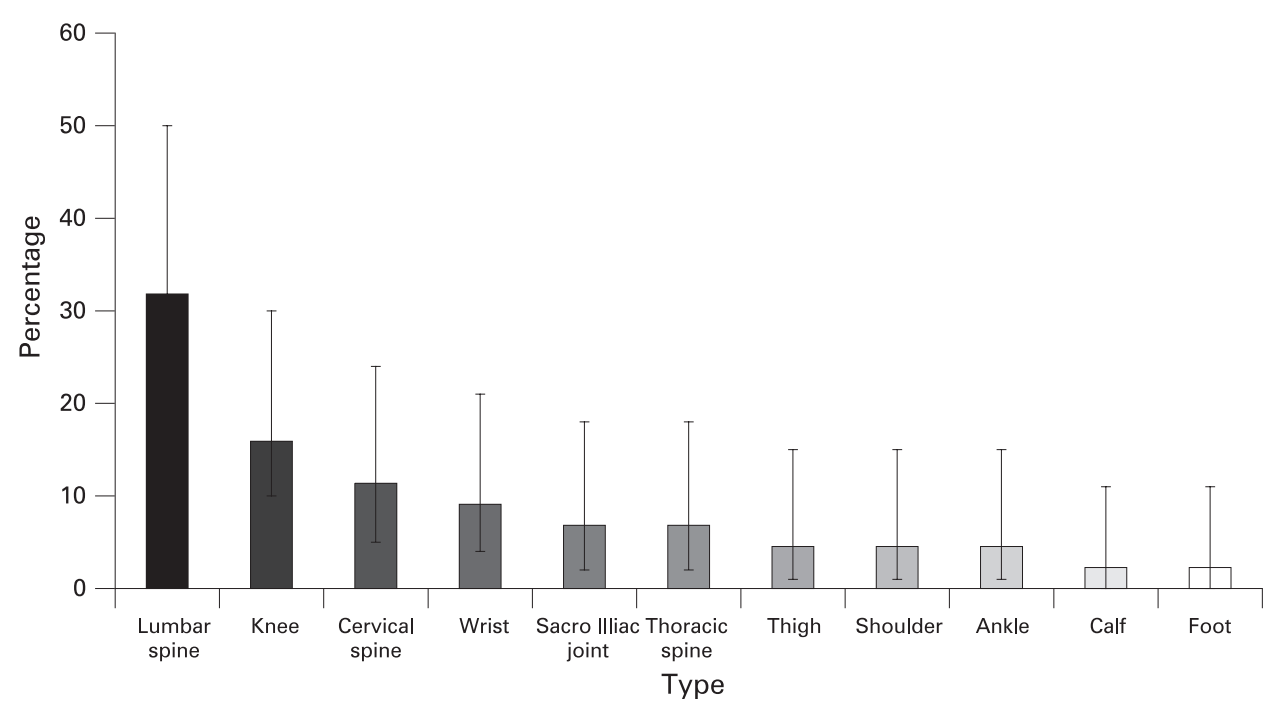

\section{Severity of injury}

Severity of injury was established by the number of training and racing hours lost due to injury as in the RIPP study. ${ }^{12}$ The number of hours completed by the injured subject was compared with the mean number of hours completed by the non-injured cohort. While 21 of the 44 injuries reported caused the subjects to lose training hours, the remaining reported injuries resulted in the subjects completing more training hours than the mean of the non-injured group. Table 6 represents individual injuries and the number of injuries to each area that resulted in the subjects completing increased or decreased racing and training.

Lumbar spine injuries were examined specifically, and training hours were compared with the mean that were completed by the non-injured cohort (table 7). The minimum training that was completed was $49.63 \%$ of the mean hours and was a result of a lumbar facet joint injury. Cervical injury severity ranged from subjects being able to complete between $97 \%$ and $147.3 \%$ of mean training hours with a mean value for this group of $116 \%$ of "normal training hours" completed.

\section{Sweep versus sculling injuries}

The injuries of sweep rowers (row with one oar, rotating to the right or left of the boat) compared with scullers (row with two oars) are represented in table 8 . Although there were more injuries to "scull-only" rowers, when this was adjusted for the number of subjects in each category, the differences were not

Table 3 Types of injuries received

\begin{tabular}{llc}
\hline Injury type & Injuries & $\%(95 \%$ Cl) \\
\hline Facet joint injury & 14 & $31.8(20$ to 46$)$ \\
Tendonitis & 12 & $27.3(16.8$ to 41.3$)$ \\
SIJ & 3 & $6.8(2.3$ to 18.2$)$ \\
Lumbar disc & 5 & $11.4(5$ to 24$)$ \\
Muscle strain & 5 & $11.4(5$ to 24$)$ \\
Joint impingement & 1 & $2.3(0.4$ to 11.8$)$ \\
Compartment & 1 & $2.3(0.4$ to 11.8$)$ \\
syndrome & 1 & $2.3(0.4$ to 11.8$)$ \\
Contusion & 1 & $2.3(0.4$ to 11.8$)$ \\
Fracture & 1 & $2.3(0.4$ to 11.8$)$ \\
PFJ syndrome & 1 & \\
Total & 44 &
\end{tabular}

PFJ, patellofemoral joint; SIJ, sacro-iliac joint. significant $\left(\chi^{2}\right.$ with $\left.2 \mathrm{df}=2.32, \mathrm{p}=0.32\right)$. When the spinal injuries were subdivided into lumbar, cervical and thoracic, the numbers were too small for analysis.

\section{DISCUSSION \\ Injury definition}

The definition selected for this study was adapted from the RIPP study ${ }^{12}$ and reflects a sport that involves regular competition, that is, rugby. However, the results of this study suggest that only one of the subcategories defined injury. Races in rowing are so infrequent that only one injury caused a subject to miss racing. It is also clear when examining training hours lost to injury, that many rowers actually complete more hours when injured, which is reflective of the large volume of crosstraining completed by rowers, particularly in winter months. The study suggests that injury caused the rower to change training rather than reduce hours. Thus, for future studies, the most accurate definition may be noted by a visit to a health professional. This narrow definition has been used previously in examination of injuries in amateur horse racing where competition or racing is very infrequent ${ }^{14}$ and may be the most appropriate in rowers.

\section{Injury incidence}

The primary objective of this study was to establish an injury rate in international rowers over a 12 -month period and this was found to be $3.67 / 1000 \mathrm{~h}$ of combined training and competing with a mean of 2.2 (1.24) injuries sustained by each athlete over the 12-month period. Comparison of the rate of injuries sustained by the study subjects with previous work is difficult, primarily because of the lack of published prospective cohort studies in rowing. Further, there is a general paucity of prospective injury studies in non-contact sports, with the largest number of prospective studies seen in sports such as soccer and rugby. The higher risk of catastrophic injuries such as cervical fractures, general fractures and acquired brain injuries may have driven the desire to investigate risk factors for injury in these sports.

The injury rate of $3.67 / 1000 \mathrm{~h}$ of contact with rowing competition and training is higher than that in distance running at $2.5 / 1000 \mathrm{~h}$ and lower than middle distance running and sprinting at 5.6 to $5.8 / 1000 \mathrm{~h} .{ }^{15}$ Although rowers would race over $2 \mathrm{~km}$, which would take between 6 and $8 \mathrm{~min}$ in 
Table 4 Relationship between number of injuries and training volume

\begin{tabular}{lllll}
\hline Month & Injuries & Mean training hours & Total training hours & Injury rate per $\mathbf{1 0 0 0} \mathbf{h}$ with $\mathbf{9 5 \%} \mathbf{~ C I}$ \\
\hline Nov & 14 & 71.34 & 1426.8 & $9.81(5.4$ to 16.5$)$ \\
Dec & 8 & 70.14 & 1402.8 & $5.70(2.5$ to 11.2$)$ \\
Jan & 7 & 69.54 & 1390.8 & $5.03(2$ to 10.4$)$ \\
Feb & 2 & 62.6 & 1252 & $1.60(0.2$ to 5.7$)$ \\
Mar & 3 & 64.12 & 1282.4 & $2.34(0.5$ to 6.8$)$ \\
Apr & 1 & 65.12 & 1302.4 & $0.77(0.1$ to 4.3$)$ \\
May & 3 & 54.25 & 1085 & $2.51(0.6$ to 8.1$)$ \\
June & 1 & 54.28 & 1085.6 & $0.92(2.3$ to 5.1$)$ \\
July & 0 & 52.32 & 1046.4 & 0.00 \\
Aug & 0 & 23.47 & 469.4 & 0.00 \\
Sept & 3 & 25.44 & 508.8 & $5.90(1.2$ to 17.3$)$ \\
Oct & 2 & 35.42 & 708.4 & $2.82(0.4$ to 10.2$)$ \\
\hline
\end{tabular}

international athletes, much of their training, particularly during the winter season, would be based on building endurance so the rate may be more closely compared with distance running. The results of this study are also higher than that of volleyball at 2.6/1000 $\mathrm{h},{ }^{16}$ which is not a contact sport but involves rapid and forceful movements of the body both horizontally and vertically ${ }^{16}$ unlike rowing, which involves a rhythmical movement that is controlled by the athlete suggesting that the lack of a surprise element may make rowers less injury prone and therefore these results in a little surprising. Rowing compares well with sailing, which notes a higher injury rate at $8.8 / 1000 \mathrm{~h}$, although a proportion of these injuries included impact with boat hardware. ${ }^{17}$

A notable finding of this study was the volume of time spent training (mean of $645.27 \mathrm{~h}$ ) compared with competing (mean of $3.07 \mathrm{~h}$ ) and that none of the injuries reported were sustained during competition. When compared with other sports with a very high training to competing ratio such as boxing, rowing compares poorly with boxing, which reports an injury rate of 2 / 1000 h. ${ }^{18}$ In addition to this, when training-only injuries were analysed in professional rugby, again, rowing compared poorly with rugby, demonstrating a training injury rate of $2 / 1000 \mathrm{~h} .{ }^{19}$ Although the injury rate established in this study generally compares well to collision or contact sports such as soccer (9.4/ $1000 \mathrm{~h})^{20}$ and Gaelic football $(13.5 / 1000 \mathrm{~h}),{ }^{21}$ this is not always the case, and some contact sports report a lower injury rate. ${ }^{22}$ So, it may be argued that when rowing is compared with sports with similar training to competing ratio and that do not involve collision with other athletes, the injury rate is comparatively high.

\section{Area and type of injury}

The study aimed not only to produce an injury rate but also a profile of the types of injury sustained by the cohort. The area in which injury was most frequently reported was the lumbar spine, which constituted $31.82 \%$ of total injuries reported, and this would be in agreement with previous studies that reported lumbar spine as the area most frequently injured in rowers. ${ }^{1-3}$ However, the results of this study are slightly higher than those previously reported in elite rowers at $15.2 \%$ of total (women) and $25 \%$ of total (men), ${ }^{1}$ although comparison may be affected as the previous study examined "elite" rowers rather than fulltime international rowers whose training and racing exposure may have been lower, although the literature did not cite contact hours.

Although lower back pain is a common injury in the general population with a lifetime incidence frequently reported in the normal population, it must be noted that injuries were all new within a 12-month period and were directly as a result of rowing training or competing. Lumbar spine pain is a debilitating injury, and such a high incidence should be considered carefully, particularly as all the cohort were full-time professional athletes and as such could consider the injury to be occupational. The biomechanics of the rowing stroke involve repeated loading to the lumbar spine in flexed and rotated position with high compressive and shear forces measured in the lumbar spine of rowers, ${ }^{23}$ which has been noted as a high risk activity for lumbar spine injury. The injury highlighted that although high volumes of "core stability" training were completed by the cohort, it did not seem to have a protective effect on the lumbar spine. There is disparity in description of

Table 5 Type of training activity per month and relationship to injury rate

\begin{tabular}{|c|c|c|c|c|c|c|c|}
\hline Month & Boat & Ergometer & $\begin{array}{l}\text { Heavy } \\
\text { weights }\end{array}$ & $\begin{array}{l}\text { Light } \\
\text { weights }\end{array}$ & $\begin{array}{l}\text { Core } \\
\text { stability }\end{array}$ & Flexibility & Number of injuries \\
\hline November & 6.65 & 2.83 & 2.08 & 0.65 & 3.675 & 4.9 & 14 \\
\hline December & 7.85 & 2.3 & 2.33 & 0.5 & 2.95 & 4.525 & 8 \\
\hline January & 7.33 & 1.95 & 1.9 & 0.65 & 2.825 & 5.125 & 7 \\
\hline February & 8.63 & 2.13 & 2 & 0.7 & 2.925 & 4.45 & 2 \\
\hline March & 8.4 & 2.3 & 1.925 & 0.825 & 2.95 & 4.65 & 3 \\
\hline April & 9.8 & 1.15 & 1.6 & 0.55 & 2.225 & 4.325 & 1 \\
\hline May & 11.05 & 0.225 & 0.8 & 1.4 & 2.6 & 3.775 & 3 \\
\hline June & 10.15 & 0.15 & 0.45 & 1.325 & 2.425 & 3.375 & 1 \\
\hline July & 9.4 & 0.3 & 0.625 & 0.15 & 1.175 & 3.575 & 0 \\
\hline August & 1.4 & 0.15 & 0.225 & 0.15 & 0.825 & 0.925 & 0 \\
\hline September & 1.975 & 1 & 0.725 & 0.3 & 0.9 & 1.5 & 3 \\
\hline October & 3.525 & 1.225 & 1.225 & 0.225 & 1.225 & 2.45 & 2 \\
\hline
\end{tabular}

Values are the mean number of sessions per week of each activity. 
Table 6 Individual injuries and proportion that increased or decreased training or racing as a result

\begin{tabular}{|c|c|c|c|}
\hline \multirow[b]{2}{*}{ Site } & \multirow[b]{2}{*}{ Type } & \multicolumn{2}{|c|}{ Training plus racing hours } \\
\hline & & Increased & Decreased \\
\hline Ankle & Tendonitis & 1 & 1 \\
\hline C spine & Facet joint & 4 & 1 \\
\hline Calf & Tendonitis & & 1 \\
\hline Foot & Fracture & 1 & \\
\hline Knee & PFJ & & 1 \\
\hline \multirow[t]{4}{*}{ L spine } & Contusion & & 1 \\
\hline & Disc & 2 & 2 \\
\hline & Facet joint & 2 & 5 \\
\hline & Muscle strain & 2 & \\
\hline Shoulder & Tendonitis & 1 & 1 \\
\hline SIJ & Dysfunction & & 3 \\
\hline T spine & Dysfunction & 1 & 2 \\
\hline Thigh & Muscle strain & 1 & 1 \\
\hline \multirow[t]{3}{*}{ Wrist } & Compartment syndrome & 1 & \\
\hline & Tendonitis & 1 & 2 \\
\hline & Total & 17 & 21 \\
\hline
\end{tabular}

C, cervical; L, lumbar; PFJ, patellofemoral joint; SIJ, sacro-iliac joint; T, thoracic.

"core stability" training with no clear definition given in the study, although specific exercises were given on the IARU programme. It may have been interpreted differently by study subjects as they were simply required to complete number of hours of "core stability" training.

The second most common injury cited was to the knee, which at $15.91 \%$ of total injuries is slightly higher than that previously reported at $12.9 \%$ (men) and $9.3 \%$ (women), ${ }^{1}$ although comparison should be made with caution due to the different cohort profile as described above.

Most striking was the high number of cervical spine injuries reported at $11.36 \%$ of total injuries. Injuries have been previously reported to the cervical spine at $1.7 \%$ (men) and $1 \%$ (women) of total injuries reported with total injuries to the spine reported as $34 \%$ (men) and $23.1 \%$ (women). ${ }^{1}$ However, while this finding is notable, it must be interpreted with caution as the severity of such injuries are impossible to interpret clearly with the present methodology. More research is needed in this area.

The findings of this study demonstrated that $50 \%$ of injuries were to the spine, which is much higher than previously reported and it was further noted that $31.8 \%$ of injuries reported were facet or apophyseal injuries to the spine or that $11.4 \%$ of injuries were lumbar disc injury. Such injuries are complex, and it could be argued that successful management of such is much more challenging than muscle or ligament tears, presenting the rowers with greater risk of not recovering fully from injury. However, it must also be noted that a considerable proportion of spinal injuries were diagnosed as facet joint injuries, based on clinical examination alone. Such an injury would be commonly diagnosed by a physiotherapist with manual therapy training as a result of examination findings, which included stiff and/or painful cervical rotation and side flexion in particular; unilateral presentation of pain; pain and/or
Table 7 Number of training hours completed by subjects who sustained lumbar spine injury

\begin{tabular}{lllcr}
\hline Injury type & $\begin{array}{l}\text { Training and } \\
\text { racing hours } \\
\text { completed }\end{array}$ & $\begin{array}{l}\text { Training and racing } \\
\text { hours completed } \\
\text { by whole cohort }\end{array}$ & $\begin{array}{l}\text { Per cent of } \\
\text { mean } \\
\text { training }\end{array}$ & $\begin{array}{l}\text { +/- change } \\
\text { in training }\end{array}$ \\
\hline Contusion & 49 & 63.19 & 77.54 & -22.46 \\
Disc & 40.7 & 79.05 & 51.49 & -48.51 \\
Disc & 68 & 63.3 & 107.42 & 7.42 \\
Disc & 92 & 64.3 & 143.08 & 43.08 \\
Disc & 50.5 & 56.44 & 89.48 & -10.52 \\
Facet joint & 97.7 & 79.05 & 123.59 & 23.59 \\
Facet joint & 78 & 79.05 & 98.67 & -1.33 \\
Facet joint & 52.5 & 79.05 & 66.41 & -33.59 \\
Facet joint & 52.4 & 64.3 & 81.49 & -18.51 \\
Facet joint & 61.4 & 66.7 & 92.05 & -7.95 \\
Facet joint & 33.1 & 66.7 & 49.63 & -50.37 \\
Facet joint & 44.5 & 35.25 & 126.24 & 26.24 \\
Muscle & 67.4 & 63.3 & 106.48 & 6.48 \\
strain & & & & \\
Muscle & 26.8 & 25.1 & 106.77 & 6.77 \\
strain & & & & \\
\hline
\end{tabular}

stiffness of intervertebral accessory motion of the facet joint on palpation. As with many injuries noted in the study, accuracy could be enhanced with confirmation of clinical hypothesis with the aid of tools such as imaging, and this should be considered for further studies. Of note, there were no reported incidences of stress fractures in the ribs of the cohort, which has previously been reported as between $12.9 \%, 22.6 \%$ and $8.7 \%{ }^{6}$ of total reported injuries. The fact that wrist injuries were merely reported as tendonitis provides limited information as clinical observation would present a more specific diagnosis of de Quervain's tenosynovitis in rowers. ${ }^{24}$ Further studies would benefit from more comprehensive diagnosis.

The fact that 35 of the injuries were acute or non-recurring seems to be high considering that international rowers would have been exposed to a high training volume over a number of years. It would be expected that more injuries would have been experienced previously as risk factors should be similar. However, this may have been an unusual year (Olympic Games year), and most of the athletes had progressed from full- or part-time employment or study, to full-time training in this year, and it is likely that training volumes had increased for many. Without previous exposure data, it is not possible to determine if such a transition was a major risk factor for injury but would merit further study.

\section{Time of injury and risk factors}

The highest number of injuries occurred during winter training in November, December and January with another peak in September. This was similar to a previous finding ${ }^{1}$ which also found another peak in May and June which may be viewed with caution as it was conducted in the southern hemisphere and may have been due to a different type of training and racing schedule. November, December and January are traditionally

Table 8 Comparison of injury rates in scullers and sweep rowers

\begin{tabular}{llllll}
\hline Boat type & Subjects & Total injuries & L spine injuries & C spine injuries & T spine injuries \\
\hline Scull only & 10 & 27 & 8 & 5 & 1 \\
Sweep only & 8 & 14 & 5 & 0 & 2 \\
Scull and sweep & 2 & 3 & 1 & 0 & 0 \\
\hline
\end{tabular}

C, cervical; L, lumbar; $T$, thoracic. 
associated with a lower volume of boat training and more land training due to weather and daylight restrictions associated with the winter months in Ireland, suggesting that land rather than boat training presents increased risk of injury for rowers.

Although the highest injury rate was in November (14 reported injuries), which also corresponded with the time of the highest volume of training in terms of contact hours, this was a non-significant association. This is in contrast to previous studies, ${ }^{25}$ which demonstrated increased odds of injury for each arbitrary unit increase in training load. However, a significant correlation was found between time spent ergometer training, heavy weight training and core stability training and risk of injury. Ergometer training and heavy weight training have been previously cited as injury risk factors in earlier studies ${ }^{3}$, although core stability training is a surprising finding as it is traditionally introduced into programmes in an effort to stabilise the trunk and reduce injury risk, particularly to the spine. However, there is a lack of consensus as to what constitutes "core stability training", and it has been interpreted widely to include low load spinal stability exercises to high load strengthening exercises for the trunk, which may explain this finding and which merits further study in this area. Time spent ergometer training had the most significant impact on injury risk, and this confirms biomechanical observations that the loading to the joints in ergometer sessions is different to the patterns seen on the water. ${ }^{26} 27$ This finding highlights the need for further research, particularly as rowers would traditionally spend many hours training on the ergometer and also because the ergometer is frequently used as a selection tool by coaches and team managers. In general, the findings suggest that further investigation into rowers' land training methods is warranted and the risk versus benefit ratio should be considered, particularly when considering lumbar spine injury.

\section{Severity of injury}

One of the most notable findings from the study was that time lost from racing or training is a very poor indicator of injury severity. Time lost was selected as the outcome measure as it is seen frequently in sports injury epidemiology, including the RIPP study. Many injured subjects were able to complete more that the mean training volume completed by the non-injured cohort. There are a number of likely reasons for this finding. Most of the injuries were sustained in the winter months when the largest volume of cross-training takes place. It is likely that injured subjects replaced one type of training with another when injured, in a bid to maintain fitness in such an important training and selection year. More intense sessions such as heavy weight training are likely to be replaced by an aerobic-based session in an injured subject which may, by definition, involve more time but less intensity. Thus, a more accurate picture of injury severity would be given by exact analysis of how the injury results in training programme change from that scheduled in terms of intensity, frequency and duration. The severity of cervical spine injury is poorly represented in this study as, although all subjects reporting this injury fulfilled the required definition, all but one subject actually completed more than the mean training hours. When the lumbar spine, in particular, is examined, it is surprising that subjects with a lumbar disc injury are able to complete such large volumes of training. This may suggest inaccuracy in diagnosis but would be clarified in future studies by a more comprehensive analysis of the effect of injury on training patterns rather than volume.

\section{What is already known on this topic}

There has been limited research into rowing injury epidemiology with no prospective studies that also examine risk factors.

\section{What this study adds}

This study examined injury profile in international rowers during an Olympic year. The study demonstrated that international rowers are at higher risk of injury than that reported in many noncontact sports and some contact sports. The risk of lumbar spine injury for international rowers over a 12-month period is notable.

\section{Sweep versus sculling injuries}

The ratio of sweep to sculling injuries is a little surprising. The rotational aspect of sweep rowing which is hypothesised to load the lumbar spine greater than in sculling has frequently been noted as a risk factor for injury by clinicians. The data does not appear to support this with a similar number of scullers sustaining lumbar injuries. It is notable that only scullers sustained cervical spine injuries. A reason for this could be that steering demands on scullers require them to look behind them at regular intervals, thus rotating their cervical spine. However, all rowers in the cohort trained in "coxless" boats, meaning more individuals than the scullers were steering boats.

\section{Limitations of the study}

The primary limitation of the study was the small number of subjects. However, this number is representative of a full international rowing team of a moderately sized rowing country and as such presented a representative sample of international standard. The lack of such a previous study merited commencement of this project, and the small sample size would be similar to previous studies which are the first to conduct a prospective cohort study in other sports. ${ }^{16} 17$ Another limitation was that although the study was prospective, interviews on a monthly basis may have introduced an element of recall bias. However, telephone interviews were time consuming and costly especially as the athletes were frequently out of the country attending training camps, and lack of funding limited other methods. Such a study method had been previously published. ${ }^{20}$ However, all athletes kept training diaries and were given a training schedule by their coach that only changed on a monthly basis, so it was assumed that exposure data was accurate. An objective of the study was to develop a research instrument to collect data regarding injury and training and competition exposure in rowers. Future studies would merit a web-based system which would allow weekly exposure and injury data to be recorded.

\section{Conclusion}

This is the first study to prospectively follow up international rowers over a 12 -month period, and no other studies of this nature have been published in rowing. International rowers are exposed to a very high training volume and low competition exposure and are at higher risk of injury than most non-contact sports and some contact sports. The high risk of lumbar spine injury and the significant association of high volume of ergometer training to injury risk merit further research to reduce time and competition lost to injury.

Competing interests: None. 


\section{REFERENCES}

1. Hickey GJ, Fricker P, McDonald WA. Injuries to elite rowers over a 10-year period. Med Sci Sports Exerc 1997;29:1567-72.

2. Howell DW. Musculoskeletal profile and incidence of musculoskeletal injuries in lightweight women rowers. Am J Sports Med 1984;12:278-82.

3. Teitz CC, O'Kane J, Lind BK, et al. Back pain in intercollegiate rowers. Am J Sports Med 2002;30:674-9

4. Teitz CC, O'Kane J, Lind BK. Back pain in former intercollegiate rowers. A long-term follow-up study. Am J Sports Med 2003;31:590-5.

5. Teitz CC, O'Kane J, Lind BK. Effect of pre-existing back pain on the incidence and severity of back pain in intercollegiate rowers. Am J Sports Med 2003;31:80-2.

6. Dragoni S, Giombini A, Di Cesare A, et al. Stress fractures of the ribs in elite competitive rowers: a report of nine cases. Skeletal Radiol 2007;36:951-4.

7. Warden SJ, Gutschlag FR, Wajswelner H, et al. Aetiology of rib stress fractures in rowers. Sports Med 2002;32:819-36.

8. Slipman CW, Patel RK, Vresilovic EJ, et al. Osseous stress reaction in a rower diagnosed with positron emission tomography (PET): a case report. Pain Physician 2001; 4:336-42.

9. Galilee-Belfer A, Guskiewicz KM. Stress fracture of the eighth rib in a female collegiate rower: a case report. J Athl Train 2000;35:445-9.

10. Karlson KA. Rib stress fractures in elite rowers. A case series and proposed mechanism. Am J Sports Med 1998;26:516-9.

11. Christiansen E, Kanstrup IL. Increased risk of stress fractures of the ribs in elite rowers. Scand J Med Sci Sports 1997;7:49-52.

12. Waller AE, Feehan M, Marshall SW, et al. The New Zealand injury and performance project: 1. Design and methodology of prospective follow up study. Br J Sports Med 1994;24:223-8.

13. Altman DG, Macken D, Bryant TN, et al. Statistics with confidence. 2nd edn. London: BMJ Books, 2000.
14. Balendra G, Turner $M$, McCrory $P$, et al. Injuries in amateur horse racing (point to point racing) in Great Britain and Ireland during 1993-2006. Br J Sports Med 2007:41:162-6.

15. Wiklander J. Injuries in runners. Am J Sports Med 1987;15:168-71.

16. Verhagen EALM, Van Der Beek AJ, Bouter LM, et al. A one season prospective cohort study of volleyball injuries. Br J Sports Med 2004;38:477-81.

17. Neville VJ, Molloy J, Brooks JHM, et al. Epidemiology of injuries and illnesses in America's Cup yacht racing. Br J Sports Med 2006;40:304-12.

18. Zazryn T, Cameron P, McCrory P. A prospective cohort study of injury in amateur and professional boxing. Br J Sports Med 2006;40:670-4.

19. Brooks JHM, Fuller CW, Kemp SPT, et al. Epidemiology of injuries in English professional rugby union: part 2 training injuries. Br J Sports Med 2005;39:767-75.

20. Walden M, Hagglund M, Ekstrand J. UEFA Champions League study: a prospective study of injuries in professional football during the 2001-2002 season. Br J Sports Med 2005;39:542-6.

21. Wilson F, Caffrey $S$, King $E$, et al. A 6-month prospective study of injury in Gaelic Football. Br J Sports Med 2007; 41:317-21.

22. Giza E, Mithofer K, Farrell L, et al. Injuries in women's professional soccer. Br J Sports Med 2005;39:212-6.

23. Morris FL, Smith RM, Payne WR, et al. Compressive and shear force generated in the lumbar spine of female rowers. Int J Sports Med 2000;21:518-23.

24. Secher NH, Voliantis S. Handbook of sports medicine and science. Rowing. Oxford: Blackwell Publishing, 2007.

25. Gabbett TJ, Domrow N. Relationship between training load, injury, and fitness in sub-elite collision sport athletes. J Sports Sci 2007;25:1507-19.

26. Lamb DH. A kinematic comparison of ergometer and on-water rowing. Am J Sports Med 1989;17:367-73.

27. Dawson RG, Lockwood RJ, Wilson JD, et al. The rowing cycle: sources of variance and invariance in ergometer and on-the water performance. J Mot Behav 1998;30:33-43. 